\title{
Advancing understanding and identifying strategies for sustaining evidence-based practices: a review of reviews
}

\author{
Sarah A. Birken ${ }^{*}$ (D), Emily R. Haines ${ }^{2}$, Soohyun Hwang ${ }^{2}$, David A. Chambers ${ }^{3}$, Alicia C. Bunger ${ }^{4}$ and Per Nilsen ${ }^{5}$
}

\begin{abstract}
Background: Implementation science has focused mainly on the initial uptake and use of evidence-based practices (EBPs), with less attention to sustainment-i.e., continuous use of these practices, as intended, over time in ongoing operations, often involving adaptation to dynamic contexts. Declining EBP use following implementation is welldocumented yet poorly understood. Using theories, models, and frameworks (TMFs) to conceptualize sustainment could advance understanding. We consolidated knowledge from published reviews of sustainment studies to identify TMFs with the potential to conceptualize sustainment, evaluate past uses of TMFs in sustainment studies, and assess the TMFs' potential contribution to developing sustainment strategies.

Methods: We drew upon reviews of sustainment studies published within the past 10 years, evaluated the frequency with which included articles used a TMF for conceptualizing sustainment, and evaluated the relevance of TMFs to sustainment research using the Theory, Model, and Framework Comparison and Selection Tool (T-CaST). Specifically, we examined whether the TMFs were familiar to researchers, hypothesized relationships among constructs, provided a face-valid explanation of relationships, and included sustainment as an outcome.
\end{abstract}

Findings: Nine sustainment reviews referenced 648 studies; these studies cited 76 unique TMFs. Only 28 TMFs were used in more than one study. Of the 19 TMFs that met the criteria for T-CaST analysis, six TMFs explicitly included sustainment as the outcome of interest, 12 offered face-valid explanations of proposed conceptual relationships, and six identified mechanisms underlying relationships between included constructs and sustainment. Only 11 TMFs performed adequately with respect to all these criteria.

Conclusions: We identified 76 TMFs that have been used in sustainment studies. Of these, most were only used once, contributing to a fractured understanding of sustainment. Improved reporting and use of TMFs may improve understanding of this critical topic. Of the more consistently used TMFs, few proposed face-valid relationships between included constructs and sustainment, limiting their ability to advance our understanding and identify potential sustainment strategies. Future research is needed to explore the TMFs that we identified as potentially relevant, as well as TMFs not identified in our study that nonetheless have the potential to advance our understanding of sustainment and identification of strategies for sustaining EBP use.

Keywords: Sustainment, Sustainability, Systematic reviews, Theories, models, and frameworks

\footnotetext{
* Correspondence: sbirken@wakehealth.edu

'Department of Health Policy and Management, Gillings School of Global

Public Health, The University of North Carolina at Chapel Hill, 1103E

McGavran-Greenberg, 135 Dauer Drive, Campus Box 7411, Chapel Hill, NC

27599-7411, USA

Full list of author information is available at the end of the article
}

(c) The Author(s). 2020 Open Access This article is licensed under a Creative Commons Attribution 4.0 International License, which permits use, sharing, adaptation, distribution and reproduction in any medium or format, as long as you give appropriate credit to the original author(s) and the source, provide a link to the Creative Commons licence, and indicate if changes were made. The images or other third party material in this article are included in the article's Creative Commons licence, unless indicated otherwise in a credit line to the material. If material is not included in the article's Creative Commons licence and your intended use is not permitted by statutory regulation or exceeds the permitted use, you will need to obtain permission directly from the copyright holder. To view a copy of this licence, visit http://creativecommons.org/licenses/by/4.0/ The Creative Commons Public Domain Dedication waiver (http://creativecommons.org/publicdomain/zero/1.0/) applies to the data made available in this article, unless otherwise stated in a credit line to the data. 


\section{Contributions to the literature}

- Our review identified theories, models, and frameworks used in sustainment research.

- Our review assessed the relevance of theories, models, and frameworks that have been used in extant sustainment research for advancing the understanding of sustainment.

- Our review identified theories that explain relationships among included constructs and hence may help inform strategies for sustainment in practice.

\section{Background}

Implementation science has emerged as a vital, multidisciplinary research field in the wake of the evidencebased movement [1]. Thus far, research in the field has focused mainly on identifying factors affecting the initial uptake and use of evidence-based practices (EBPs). Less attention has been given to the sustainment of implemented practices-i.e., continuous evidence-based practice (EBP) use, as intended, over time in ongoing operations, often involving adaptation to dynamic contexts [2-4]. Many EBPs are adopted, only for their benefit to wane [5-7]. The declining quality, intensity, and comprehensiveness of EBP use following implementation are well-documented [8-10], but how and why EBP use is sustained remains unclear.

There are several reasons for the limited knowledge about EBP sustainment. First, there is a lack of conceptual clarity in the literature [11]: Researchers use a range of terms to describe sustainment, including sustainability, which is a related, but distinct, term that refers to preparedness for sustained use or the characteristics of a new practice which will enhance its sustainment [12, 13]. Other terms that may reflect an ongoing process expected to result in sustainment include, for example, continuation, durability, institutionalization, sustained use, and routinization [8]. Hence, it is possible that the same underlying concept (i.e., sustainment) is described using different terms (synonymy) or the same key terms might be defined in different ways (polysemy). The use of imprecise concepts and terms makes knowledge exchange and learning on this topic difficult. Second, there are methodological challenges to studying sustainment: The post-implementation duration required to achieve sustainment is unclear [8], and the period required for assessing sustainment may exceed grant funding periods. Third, knowledge regarding EBP sustainment may be limited by the lack of an agreed-upon theory, model, or framework (hereafter referred to in combination as TMFs).

Using TMFs to conceptualize sustainment could alleviate issues related to synonymy and polysemy and offer a structure for organizing and comparing findings across study settings. In addition, TMFs could help guide all phases of sustainment research and practice, including assessment of the form and degree of sustainment, identification of determinants of sustainment, selection of strategies for promoting sustainment, and evaluation of sustainment-related outcomes [14]. In particular, theories (in contrast to models and frameworks, which do not specify theoretical relationships in a way that explains how or why EBPs are sustained) are needed to suggest strategies for promoting EBP sustainment $[2,13]$.

The extent to which TMFs are used to advance understanding of sustainment is unclear. We consolidated knowledge from published reviews of healthcare sustainment studies to identify TMFs with the potential to conceptualize sustainment, evaluate past uses of these TMFs in sustainment studies, and assess the TMFs' potential contribution to the development of sustainment strategies. A recent systematic review by Penno and colleagues identified and analyzed existing TMFs that focus on the sustainability of EBPs in specific healthcare settings [15]. Penno and colleagues' review examined the concepts and factors associated with sustainability within the TMFs (i.e., what influences sustainment). Our review complements Penno and colleagues' review by identifying TMFs that explain the relationships included among constructs to inform sustainment strategies (i.e., why constructs are thought to influence sustainment). We conclude by recommending TMFs that have the greatest potential to advance understanding of sustainment in future research and thereby may contribute to identifying potential strategies for EBP sustainment.

\section{Method}

\section{Search strategy}

To identify TMFs that have been used in healthcare sustainment research, we drew upon recently published reviews of sustainment studies. To identify reviews, we followed an approach similar to that of Moore et al.'s search for knowledge syntheses of sustainability in healthcare interventions [16]: We used the PubMed search filter for reviews to identify articles with the terms "sustainability," "sustainment," "durability," "institutionalization," "routinization," "continuation," or "sustained" in the title and published in the past 10 years. We used this range of terms to account for the common use of different terms to describe the concept of sustainment [8].

\section{Inclusion criteria}

To be included, we required articles to (1) be written in English, (2) be published in the past 10 years, (3) review articles of sustainment studies, and (4) report on the use of TMFs among included studies. 


\section{Study selection}

Three authors selected records for inclusion in the study. These authors conducted title, abstract, and fulltext review, searching for inclusion of sustainment as a key construct of interest. The three authors resolved discrepancies through discussions, and they reached consensus. Two authors then reviewed the full text of the remaining articles, confirming evidence of reviews of sustainment studies with reports of TMFs in each record.

\section{Data abstraction and analysis TMFs used in sustainment studies}

We reported the frequency with which included articles used a TMF for conceptualizing sustainment, identified all TMFs used by the studies included in the selected review articles, and reported the prevalence of the TMFs across studies. Although they reported on the use of TMFs in studies they included, Shigayeva and Coker (2015) [17] did not indicate the number of included studies that used TMFs, so we reviewed all 108 empirical studies included in Shigayeva and Coker (2015) [17]. From those studies, we abstracted information regarding whether a TMF was used and, if so, which TMF. Two authors independently reviewed 20\% $(n=22 / 108$ empirical studies included in Shigayeva and Coker (2015) [17]) of the articles to ensure reliability in abstraction; a single investigator abstracted information from the remaining articles. We excluded articles reporting framework development.

\section{Relevance of TMFs for understanding sustainment}

To evaluate the relevance of TMFs for understanding sustainment, we evaluated the TMFs using four criteria: degree of familiarity of the TMF to researchers, operationalized in terms of frequency or usage, and three additional criteria from the Theory, Model, and Framework Comparison and Selection Tool (T-CaST) [18], a userfriendly tool designed to help select TMFs for implementation research. T-CaST guides researchers through rating candidate TMFs' performance with respect to four domains: usability, testability, applicability, and acceptability. Our study objectives were to identify TMFs that could advance understanding of sustainment and contribute to identifying strategies for sustainment. To achieve these objectives, two authors used T-CaST to rate the performance of TMFs identified in the review from their own perspectives with respect to the following criteria:

(1) TMF is familiar to key stakeholders (i.e., implementation researchers). We defined familiarity as being used in two or more articles.
(2) TMF provides an explanation of how included constructs influence sustainment and/or each other (i.e., TMF hypothesizes relationships among constructs rather than simply listing them).

(3) TMF includes meaningful, face-valid explanations of proposed relationships (i.e., hypothesized relationships among constructs are logically consistent and plausible).

(4) TMF includes sustainment as an outcome.

Application of the first criterion left 28 TMFs we then evaluated in terms of criteria (2)-(4).

T-CaST rates TMFs 0,1 , or 2 with respect to relevant criteria, where $0=$ TMF does not fit criterion, $1=\mathrm{TMF}$ fits criterion moderately well, and $2=$ TMF fits criterion well. Thus, after limiting TMFs to the 28 cited by two or more included articles, a TMF could score from 0 (TMF does not fit any selected criteria well) to 6 (TMF fits criteria well). We excluded nine of the 28 remaining TMFs because they were too broad in scope (e.g., "theories of organizational change and innovation"), too vague to identify (e.g., "intervention theory"), or were not TMFs (e.g., "child survival sustainability assessment"). Two authors, trained implementation scientists, independently coded nine TMFs and resolved discrepancies through discussions until they reached consensus; they then individually coded the remaining 10 TMFs.

\section{Results \\ Search results}

This search yielded 733 publications. Of these, 709 publications were excluded because they were not published in English, were not published in the past 10 years, did not review sustainment studies, and/or did not report on TMF use among included studies. A subsequent review of article titles and abstracts narrowed this down to 24 publications deemed relevant. Upon full-text review, 15 additional articles were excluded because, upon closer inspection, they did not meet inclusion criteria. There remained nine review articles which contained information about 648 empirical studies of sustainment in healthcare settings. This process is summarized in Fig. 1 [8, 17, 19-25].

\section{Description of included reviews}

Table 1 displays characteristics of included reviews (systematic, scoping, and literature reviews) spanning multiple fields and disciplines, such as global health [27, 28], chronic disease [19], and communicable disease [29]. Collectively, the reviews covered from 1979 to 2017. Four reviews had indicated the quality appraisal of the articles. Six of the nine reviews were explicitly limited to English language articles published. Four of the nine 


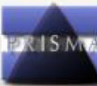

PRISMA 2009 Flow Diagram

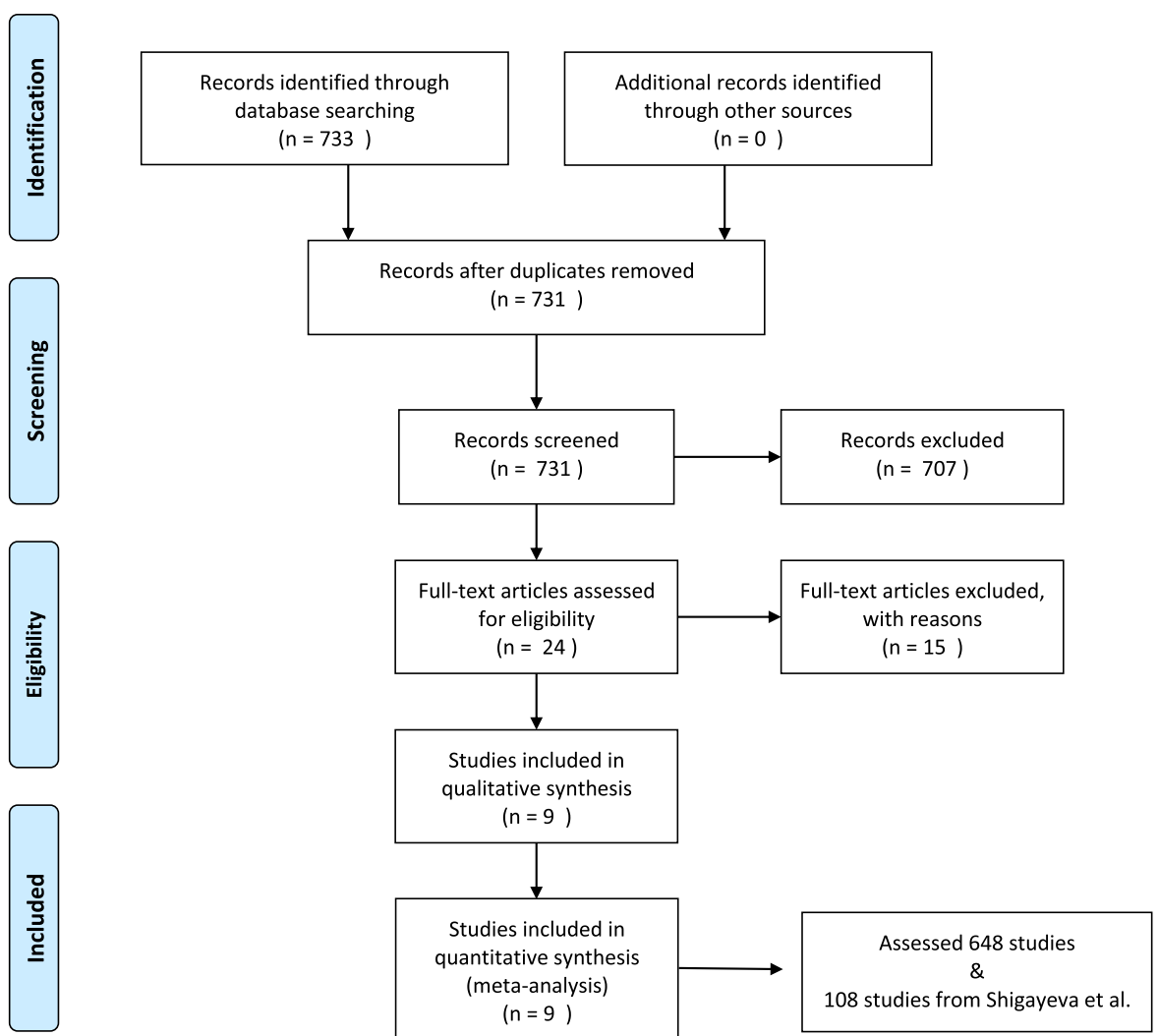

Fig. 1 PRISMA 2009 flow diagram

reviews reported formally assessing the quality of the included articles.

\section{TMF use}

Seven of the nine identified reviews reported the proportion of included studies that explicitly used a TMF [8, 17, 19-24]; an estimated 194/478 (41\%) of the studies included in these seven reviews used a TMF to study sustainment (see Table 1 for details on estimate).

The remaining two reviews focused exclusively on articles that used TMFs to study sustainment [26, 29]. For example, Lennox et al. [26] reviewed the literature for publications reporting the use of TMFs (i.e., models, checklists, tools, processes, strategies, conceptualizations, and frameworks) and found that $37 \%(23 / 62)$ of the included studies did not report using a theory, although the included studies may have used models and/or frameworks.

Table 2 reports the 76 unique TMFs cited in the 648 studies included across the 9 reviews. The most frequently cited TMFs were diffusion of innovations ( $n=$ $16)$, ecological theories $(n=10)$, complexity theory $(n=$
$10)$, and normalization process theory $(n=6)$. Most of the TMFs that were cited across the 9 reviews $(48 / 76)$ were only used by one of the 648 studies.

\section{Relevance of TMFs used in sustainment studies}

The TMFs that we scored received ratings ranging from 2 to 5 (see Table 3). The TMF with the highest score was institutional theory, which scored 5 out of 6 . TMFs scoring 4 out of 6 included the model of institutionalization [31], diffusion of innovations theory [32], open systems theories [33], normalization process theory [29], organizational learning theory [34], the health belief model [27], network theory [35], the theory of planned behavior [28], the organizational sustainability framework [36], and the theory of organization routines [37].

Table 3 shows our evaluation of the relevance of the TMFs for conceptualizing sustainment. As can be seen from the bottom row in Table 3, compared to other rating criteria, the TMFs performed best on criterion 2, inclusion of meaningful, face-valid explanations of proposed relationships (total T-CaST score across TMFs, 29). Notably, however, the 
Table 1 Reviews of sustainment studies

\begin{tabular}{|c|c|c|c|c|c|c|}
\hline Authors (year) & Years covered & Language & $\begin{array}{l}\text { Quality } \\
\text { appraisal }\end{array}$ & $\begin{array}{l}\text { Review } \\
\text { type }\end{array}$ & Interventions of interest & $\begin{array}{l}\text { Proportion of review's } \\
\text { included studies } \\
\text { reporting TMF use }\end{array}$ \\
\hline $\begin{array}{l}\text { Tricco et al. } \\
\text { (2016) [19] }\end{array}$ & 1979-2012 & Unspecified & No & Scoping & $\begin{array}{l}\text { Chronic disease } \\
\text { management }\end{array}$ & $\begin{array}{l}\text { "[N]one of the included } \\
\text { studies reported using a } \\
\text { framework to develop, } \\
\text { implement, or measure } \\
\text { sustainability" (p.5). [0/144] }\end{array}$ \\
\hline $\begin{array}{l}\text { Wiltsey Stirman } \\
\text { et al. (2012) [8] }\end{array}$ & $\begin{array}{l}\text { Published or in } \\
\text { press by July } 2011\end{array}$ & English & No & Systematic & $\begin{array}{l}\text { Various medical care } \\
\text { and health services, } \\
\text { mental and behavioral } \\
\text { health, health } \\
\text { promotion and public } \\
\text { health, and education }\end{array}$ & $\begin{array}{l}\text { "[F]ewer than one-third of the } \\
\text { studies that we reviewed were } \\
\text { guided by an explicit model" } \\
\text { (p.12) }[1 / 3 \times 125=41 / 125]\end{array}$ \\
\hline $\begin{array}{l}\text { Hulland et al. } \\
2015 \text { [20] }\end{array}$ & $\begin{array}{l}\text { Published or } \\
\text { available by } \\
\text { December 1, } \\
2013\end{array}$ & $\begin{array}{l}\text { English, French, } \\
\text { German, or Spanish }\end{array}$ & Yes & Systematic & Water, hygiene, and sanitation & $\begin{array}{l}\text { "[O]nly } 11 \text { of the } 36 \text { studies } \\
\text { described a behavioral model } \\
\text { or conceptual framework" } \\
\text { (p.44). [11/36 articles] }\end{array}$ \\
\hline $\begin{array}{l}\text { Lovarini et al. } \\
\text { (2013) [21] }\end{array}$ & Unspecified & English & Yes & Systematic & $\begin{array}{l}\text { Community-based } \\
\text { fall prevention }\end{array}$ & $\begin{array}{l}\text { "Three publications } \\
\text { described different } \\
\text { conceptual frameworks } \\
\text { or models of program } \\
\text { sustainability" (p.11). [3/19] }\end{array}$ \\
\hline $\begin{array}{l}\text { Hodge and } \\
\text { Turner (2016) [24] }\end{array}$ & Unspecified & English & No & Literature & $\begin{array}{l}\text { Various for } \\
\text { disadvantaged } \\
\text { communities }\end{array}$ & $\begin{array}{l}\text { "Only } 11 \text { of the articles } \\
\text { indicated that they } \\
\text { were guided by a } \\
\text { conceptual framework } \\
\text { for implementation" } \\
\text { (p.196). [11/28] }\end{array}$ \\
\hline $\begin{array}{l}\text { Iwelunmor et al. } \\
\text { (2016) [22] }\end{array}$ & 1996-2015 & English & Yes & Systematic & $\begin{array}{l}\text { Various implemented } \\
\text { in Sub-Saharan Africa }\end{array}$ & $\begin{array}{l}\text { "[Twenty-three] of the } 41 \\
\text { articles reviewed discussed } \\
\text { framing the sustainability } \\
\text { in terms of a theory or } \\
\text { conceptual framework" } \\
\text { (p.15). [23/41] }\end{array}$ \\
\hline $\begin{array}{l}\text { Schell et al. } \\
\text { (2013) [23] }\end{array}$ & $\begin{array}{l}\text { Literature spans } \\
\text { about } 20 \text { years }\end{array}$ & Unspecified & No & Literature & $\begin{array}{l}\text { Various in public } \\
\text { health }\end{array}$ & $\begin{array}{l}\text { "Some pieces highlighted } \\
\text { the relevance of institutional } \\
\text { theory, Schien's work on } \\
\text { organizational culture, or } \\
\text { diffusion of innovations" } \\
\text { (p.5). [3/85] }\end{array}$ \\
\hline $\begin{array}{l}\text { Lennox et al. } \\
\text { (2018) [26] }\end{array}$ & $\begin{array}{l}\text { Final search } \\
\text { conducted } \\
\text { September } 2017\end{array}$ & English & Yes & Systematic & $\begin{array}{l}\text { Various in health care } \\
\text { (i.e., models, checklists, } \\
\text { tools, processes, strategies, } \\
\text { conceptualizations and } \\
\text { frameworks) }\end{array}$ & $\begin{array}{l}\text { "37\% (23/62) did not have } \\
\text { an explicit link to theory" } \\
\text { (p.4). [39/62] }\end{array}$ \\
\hline $\begin{array}{l}\text { Shigayeva and } \\
\text { Coker (2015) [17] }\end{array}$ & 1980-2012 & English & No & Literature & $\begin{array}{l}\text { Communicable disease } \\
\text { programs }\end{array}$ & $\begin{array}{l}66 \%[71 / 108] \text { of empirical } \\
\text { studies included in the } \\
\text { review did not use a TMF. } \\
{[37 / 108]}\end{array}$ \\
\hline
\end{tabular}

TMF theory, model, and/or framework

dynamic sustainability framework only scored 1 on this criterion because the framework shifts between empirical statements about how sustainability occurs and normative ones about what change agents should do to sustain EBPs.

The TMFs performed worst with respect to criterion 3 (including sustainment as an outcome). For example, normalization process theory, which received a score of 1 on this criterion, proposes face-valid relationships among constructs, but the proposed antecedents to sustainment were difficult to distinguish from sustainment itself.

The TMFs also showed inconsistencies in their explanations of how constructs influence sustainment and/or each other (criterion 1; total T-CaST score across TMFs, 19). Several TMFs (e.g., open systems theories, organizational learning theory, complexity theory, and ecological theories) lacked discrete constructs that might be operationalized as antecedents to sustainment. 
Table 2 TMF cited in included studies

\begin{tabular}{|c|c|c|c|}
\hline & TMF & $\begin{array}{l}\text { Number of studies citing } \\
\text { TMF* }^{*}\end{array}$ & Review article (number of included studies citing TMF) \\
\hline 1 & Diffusion of innovations theory & 16 & $\begin{array}{l}\text { Schell et al. } 2013 \text { (1) [23]; Lovarini et al. } 2013 \text { (1) [21], } \\
\text { Lennox et al. } 2018 \text { (10) [26]; Shigayeva and Coker } 2015 \text { (2) [17]; } \\
\text { Iwelunmor et al. } 2016 \text { (1) [22]; Hulland et al. } 2015 \text { (1) [20] }\end{array}$ \\
\hline 2 & Ecological theories & 10 & $\begin{array}{l}\text { Lennox et al. } 2018 \text { (5) [26]; Shigayeva and Coker } 2015 \text { (2) [17]; } \\
\text { Iwelunmor et al. } 2016 \text { (3) [22] }\end{array}$ \\
\hline 3 & Complexity theory & 10 & Lennox et al. 2018 (9) [26]; Hodge and Turner 2016 (1) [24] \\
\hline 4 & Normalization process theory & 6 & Lennox et al. 2018 (3) [26]; Shigayeva and Coker 2015 (3) [17] \\
\hline 5 & Model of institutionalization & 6 & Shigayeva and Coker 2015 (5) [17]; Hodge and Turner (1) [24] \\
\hline 6 & Open systems theories & 5 & Lennox et al. 2018 (4) [26]; Shigayeva and Coker 2015 (1) [17] \\
\hline 7 & Conceptual framework on sustainability & 5 & Iwelunmor et al. 2016 (3) [22]; Shigayeva and Coker 2015 (2) [17] \\
\hline 8 & Dynamic sustainability framework & 4 & Iwelunmor et al. 2016 (4) [22] \\
\hline 9 & Theories of organizational change and innovation & 3 & Shigayeva and Coker 2015 (3) [17] \\
\hline 10 & Organizational theory: formation of inter-organizational relationships & 3 & Shigayeva and Coker 2015 (3) [17] \\
\hline 11 & Institutional theory & 3 & $\begin{array}{l}\text { Schell et al. } 2013 \text { (1) [23]; Lennox et al. } 2018 \text { (1) [26]; } \\
\text { Shigayeva and Coker } 2015 \text { (1) [17] }\end{array}$ \\
\hline 12 & Continuous quality improvement & 3 & Lennox et al. 2018 (3) [26] \\
\hline 13 & Organizational learning theory & 3 & Lennox et al. 2018 (1) [26]; Shigayeva and Coker 2015 (2) [17] \\
\hline 14 & World Health Organization guidelines and models & 3 & Hodge and Turner (1) [24]; Iwelunmor et al. 2016 (2) [22] \\
\hline 15 & Theory of planned behavior/theory of reasoned action & 3 & $\begin{array}{l}\text { Lennox et al. } 2018 \text { (1) [26]; Martin et al. } 2018 \text { (1) [30]; } \\
\text { Shigayeva and Coker } 2015 \text { (2) [17] }\end{array}$ \\
\hline 16 & Social learning theory/social cognitive theory & 3 & Shigayeva and Coker 2015 (3) [17] \\
\hline 17 & Network theory & 3 & Lennox et al. 2018 (2) [26]; Shigayeva and Coker 2015 (1) [17] \\
\hline 18 & Health belief model & 2 & Hulland et al. 2015 (2) [20] \\
\hline 19 & Child Survival Sustainability Assessment framework & 2 & Lennox et al. 2018 (1) [26]; Shigayeva and Coker 2015 (1) [17] \\
\hline 20 & Freire's conscientization theory & 2 & Iwelunmor et al. 2016 (1) [22]; Shigayeva and Coker 2015 (1) [17] \\
\hline 21 & Program Sustainability Index & 2 & Hodge and Turner (2) [24] \\
\hline 22 & Framework for the assessment of sustainability & 2 & Iwelunmor et al. 2016 (1) [22]; Shigayeva and Coker 2015 (1) [17] \\
\hline 23 & System dynamics & 2 & Lennox et al. 2018 (1) [26]; Shigayeva and Coker 2015 (1) [17] \\
\hline 24 & Theory of organization routines & 2 & Lennox et al. 2018 (1) [26]; Shigayeva and Coker 2015 (1 )[17] \\
\hline 25 & HIV/AIDS Program Sustainability Analysis Tool & 2 & Iwelunmor et al. (1) [22]; Shigayeva and Coker 2015 (1) [17] \\
\hline 26 & Sustainability planning model & 2 & Iwelunmor et al. (1) [22]; Shigayeva and Coker 2015 (1) [17] \\
\hline 27 & Sustainability framework for community-based dengue control projects & 2 & Hodge and Turner (1) [24]; Shigayeva and Coker 2015 (1) [17] \\
\hline 28 & Organizational sustainability framework & 2 & Shigayeva and Coker 2015 (2) [17] \\
\hline 29 & Organizational culture & 1 & Schell et al. 2013 [23] \\
\hline 30 & Intervention (program) theory & 1 & Lennox et al. 2018 [26] \\
\hline 31 & Focus on opportunity, ability, and motivation & 1 & Hulland et al. 2015 [20] \\
\hline 32 & Risk, attitude, norm, ability, self-regulation & 1 & Hulland et al. 2015 [20] \\
\hline 33 & PATH's Behavior Change Continuum & 1 & Hulland et al. 2015 [20] \\
\hline 34 & Transtheoretical model of change & 1 & Hulland et al. 2015 [20] \\
\hline 35 & Consumer purchase decision process & 1 & Hulland et al. 2015 [20] \\
\hline 36 & Elaboration of likelihood & 1 & Hulland et al. 2015 [20] \\
\hline 37 & Dimensions of social research & 1 & Hulland et al. 2015 [20] \\
\hline 38 & Knowledge dissemination and utilization framework & 1 & Lovarini et al. 2013 [21] \\
\hline 39 & Policy, research, and service delivery model for fall prevention & 1 & Lovarini et al. 2013 [21] \\
\hline 40 & Organizational theory & 1 & Lovarini et al. 2013 [21] \\
\hline 41 & Systems thinking-guided analysis framework & 1 & Iwelunmor et al. 2016 [22] \\
\hline 42 & Model of motivational processes & 1 & Iwelunmor et al. 2016 [22] \\
\hline 43 & Clinical assessment for systems strengthening framework & 1 & Iwelunmor et al. 2016 [22] \\
\hline 44 & "Train the trainer" model & 1 & Iwelunmor et al. 2016 [22] \\
\hline
\end{tabular}


Table 2 TMF cited in included studies (Continued)

\begin{tabular}{|c|c|c|c|}
\hline & TMF & $\begin{array}{l}\text { Number of studies citing } \\
\text { TMF* }\end{array}$ & Review article (number of included studies citing TMF) \\
\hline 45 & $\begin{array}{l}\text { Community-based management of acute malnutrition of the Belgian Red } \\
\text { Cross }\end{array}$ & 1 & Iwelunmor et al. 2016 [22] \\
\hline 46 & Organizational readiness to change theory & 1 & Iwelunmor et al. 2016 [22] \\
\hline 47 & In-service training improvement framework & 1 & Iwelunmor et al. 2016 [22] \\
\hline 48 & $\begin{array}{l}\text { Promoting school-community-university partnerships to enhance resilience } \\
\text { model }\end{array}$ & 1 & Hodge and Turner 2016 [24] \\
\hline 49 & Evaluation theory & 1 & Lennox et al. 2018 [26] \\
\hline 50 & Model for improvement & 1 & Lennox et al. 2018 [26] \\
\hline 51 & Adaptive management & 1 & Lennox et al. 2018 [26] \\
\hline 52 & Evidence integration triangle & 1 & Lennox et al. 2018 [26] \\
\hline 53 & Self-determination theory & 1 & Lennox et al. 2018 [26] \\
\hline 54 & Theory of change & 1 & Lennox et al. 2018 [26] \\
\hline 55 & Absorptive capacity & 1 & Lennox et al. 2018 [26] \\
\hline 56 & Dartmouth psychiatric research center implementation model & 1 & Hodge and Turner 2016 [24] \\
\hline 57 & School-wide positive behavior support continuum & 1 & Hodge and Turner 2016 [24] \\
\hline 58 & Exploration, planning, implementation, sustainment & 1 & Hodge and Turner 2016 [24] \\
\hline 59 & Community readiness model & 1 & Shigayeva and Coker 2015 [17] \\
\hline 60 & Theory of how to design effective organizations & 1 & Shigayeva and Coker 2015 [17] \\
\hline 61 & Reach effectiveness adoption implementation maintenance & 1 & Shigayeva and Coker 2015 [17] \\
\hline 62 & Model of community-based program sustainability & 1 & Shigayeva and Coker 201 5[31] \\
\hline 63 & Precede framework & 1 & Shigayeva and Coker 2015 [17] \\
\hline 64 & Communities that Care framework & 1 & Shigayeva and Coker 2015 [17] \\
\hline 65 & World Health Organization safe community model & 1 & Shigayeva and Coker 2015 [17] \\
\hline 66 & National Funding Collaborative on Violence Prevention's Theory of Change & 1 & Shigayeva and Coker $2015[17]$ \\
\hline 67 & STEP-UP framework & 1 & Shigayeva and Coker 2015 [17] \\
\hline 68 & Conceptual model of social determinants of health & 1 & Shigayeva and Coker 2015 [17] \\
\hline 69 & Sustainability benchmarks & 1 & Shigayeva and Coker 2015 [17] \\
\hline 70 & Nature of partnerships & 1 & Shigayeva and Coker 2015 [17] \\
\hline 71 & Five basic elements of program sustainability for tobacco control programs & 1 & Shigayeva and Coker 2015 [17] \\
\hline 72 & Mandiana model & 1 & Shigayeva and Coker 2015 [17] \\
\hline 73 & Sustainability checklist & 1 & Shigayeva and Coker 2015 [17] \\
\hline 74 & $\begin{array}{l}\text { Scheirer's framework to assess the development and capacity of non-profit } \\
\text { agencies }\end{array}$ & 1 & Shigayeva and Coker 2015 [17] \\
\hline 75 & Punctuated equilibrium theory & 1 & Shigayeva and Coker 2015 [17] \\
\hline 76 & Multi-level model of factors to be identified at the levels of the innovation & 1 & Shigayeva and Coker 2015 [17] \\
\hline
\end{tabular}

TMF theory, model, and/or framework

*Across 648 studies included in the nine reviews

\section{Discussion}

In our review of 9 reviews, we found that TMFs are underused in sustainment research. This finding parallels previous reports of the underuse of TMFs in implementation science more broadly [38-40]. In most of these reviews, which spanned multiple disciplines and topics, fewer than half of included studies reported using a TMF to conceptualize sustainment. This may reflect studies' focus on understanding whether an intervention was sustained, rather than determinants of sustainment [26]. As the field shifts from accumulating evidence of poor EBP sustainment to understanding determinants of sustainment, lack of TMF use in sustainment studies represents a missed opportunity to realize the benefits of using TMFs, including their potential to advance a shared understanding of how and why EBPs are sustained [14]. Among those studies that reported using a TMF, there was little convergence on which of the 76 TMFs that we identified in sustainment research to date were used. Indeed, 48 studies which used a TMF did not appear in any of the other studies. This lack of convergence may contribute to a fractured understanding of sustainment across studies, settings, and fields and may retain concerns regarding synonymy and polysemy. Improved reporting and use of TMFs across multiple studies should improve understanding of this critical topic. 
Table 3 Relevance of sustainment TMF

\begin{tabular}{cllll}
\hline TMF & $\begin{array}{l}\text { Provides an } \\
\text { explanation of }\end{array}$ & Includes & Includes & Overall \\
how included & face-valid & sustainment & as an & T-CaST \\
constructs & explanations & outcome & \\
influence & of proposed & & \\
sustainment & relationships & \\
and/or each & & & \\
other & & & \\
& & & & \\
& & &
\end{tabular}

Institutional theory enhances understanding the organizations' practice sustainment in response to three key pressures but offers limited insight into potentially influential factors at inner setting and individual levels. Its outcome is isomorphism (i.e., increasing likeness), which may be related to sustainment but is conceptually distinct.

2 Model of institutionalization

The model of institutionalization identifies six factors associated with institutionalization (e.g., standard operating routines; program champion actions). It offers face-valid explanations of proposed relationships, but it lacks a description of the mechanisms underlying those relationships, and its outcome is institutionalization (i.e., "the final stage of an innovation-diffusion process"), which may be related to sustainment but is conceptually distinct.

3 Diffusion of innovations 2 theory

Diffusion of innovations theory explains how people, as part of a social system, adopt a new idea, behavior, or product through five established adopter categories: innovators, early adopters, early majority, late majority, and laggards. It offers face-valid explanations of proposed relationships but lacks discrete constructs that might be operationalized as antecedents to sustainment, and its outcome is innovation diffusion, which is conceptually distinct from sustainment.

Open systems theories broadly propose that organizations are strongly influenced by their environments. They offered a meaningful, face-valid explanation of sustainment but do not include discrete constructs, thereby limiting our ability to operationalize or falsify the theory. Further, open systems theories are an umbrella that encompasses several theories, not a singular TMF.

5 Normalization process theory theory
Normalization process theory describes the social processes leading the routinization of EBPs. It explains relationships among included constructs but does not offer a clear conceptual distinction between "integration"/"embeddedness" and implementation.

Organizational learning theory describes a process of experience. It offers face-valid explanations of proposed conceptual relationships but lacks discrete constructs that might be operationalized as antecedents to sustainment, and its outcome is knowledge, which may be related but is conceptually distinct from sustainment.

The health belief model theorizes that people's beliefs about whether or not they are at risk for a disease or health problem and their perceptions of the benefits of taking action to reduce or avoid influence their readiness to take action. It offers face-valid explanations of proposed conceptual relationships and identifies mechanisms underlying relationships between included constructs and the outcome; however, its outcome is action, which is conceptually distinct from sustainment.

Network theory advances understanding how extant organizations embedding knowledge from 
Table 3 Relevance of sustainment TMF (Continued)

\begin{tabular}{|c|c|c|c|c|}
\hline TMF & $\begin{array}{l}\text { Provides an } \\
\text { explanation of } \\
\text { how included } \\
\text { constructs } \\
\text { influence } \\
\text { sustainment } \\
\text { and/or each } \\
\text { other }\end{array}$ & $\begin{array}{l}\text { Includes } \\
\text { meaningful, } \\
\text { face-valid } \\
\text { explanations } \\
\text { of proposed } \\
\text { relationships }\end{array}$ & $\begin{array}{l}\text { Includes } \\
\text { sustainment } \\
\text { as an } \\
\text { outcome }\end{array}$ & $\begin{array}{l}\text { Overall } \\
\text { T-CaST } \\
\text { score }\end{array}$ \\
\hline
\end{tabular}

Notes

networks affect either the flow of information and resources to individual actors or how individual actors gain prestige or influence through their positions in networks. It offers face-valid explanations of proposed conceptual relationships and identifies mechanisms underlying relationships between included constructs and the outcome; however, its outcome is relational connections, which is conceptually distinct from sustainment.

9 Theory of planned behavior

10 Organizational

sustainability framework

11 Theory of organization routines
1
1
$4 / 6$

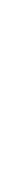

$4 / 6$

(1)

The theory of planned behavior offers face-valid explanations of proposed conceptual relationships and identifies mechanisms underlying relationships between included constructs and the outcome; however, its outcome is behavior, which may be related but is conceptually distinct from sustainment.

The organizational sustainability framework suggests that sustainability, a term that is related yet distinct from sustainment, is a function of economic, environmental, and social organizational sustainability. The framework identifies very general mechanisms underlying relationships between included constructs and the outcome, and the constructs that it includes are somewhat meaningful and face-valid if not comprehensive.

The theory of organization routines suggests that routines are developed through directions and performances among organizational members. It identifies meaningful, face-valid constructs hypothesized to facilitate routines, but it does not specify the mechanisms underlying the relationships, and its outcome is routines (i.e., ways of accomplishing organizational work), which may be related to sustainment but is conceptually distinct.

\footnotetext{
12 Complexity theory

13 Dynamic sustainability framework

14 Freire's conscientization theory

15 Sustainability planning model

16 Social learning theory/ social cognitive theory

17 Ecological theories

18 Program Sustainability Index

19 Sustainability framework for community-based dengue control projects

20 Theories of organizational change and innovation change and innovation

21 Organizational theory: formation of interorganizational relationships
}

$3 / 6$

$3 / 6$

$3 / 6$

$2 / 6$

$2 / 6$

$2 / 6$

[Eliminated (too broad)]

[Eliminated (too broad)] 
Table 3 Relevance of sustainment TMF (Continued)

\begin{tabular}{|c|c|c|c|c|c|}
\hline \multicolumn{2}{|r|}{ TMF } & \multirow[t]{2}{*}{$\begin{array}{l}\text { Provides an } \\
\text { explanation of } \\
\text { how included } \\
\text { constructs } \\
\text { influence } \\
\text { sustainment } \\
\text { and/or each } \\
\text { other }\end{array}$} & \multirow[t]{2}{*}{$\begin{array}{l}\text { Includes } \\
\text { meaningful, } \\
\text { face-valid } \\
\text { explanations } \\
\text { of proposed } \\
\text { relationships }\end{array}$} & \multirow[t]{2}{*}{$\begin{array}{l}\text { Includes } \\
\text { sustainment } \\
\text { as an } \\
\text { outcome }\end{array}$} & \multirow{2}{*}{$\begin{array}{l}\text { Overall Notes } \\
\text { T-CaST } \\
\text { score } \\
\\
\\
\\
\\
\text { [Eliminated } \\
\text { (insufficiently } \\
\text { specified)] }\end{array}$} \\
\hline 22 & $\begin{array}{l}\text { Conceptual framework } \\
\text { on sustainability }\end{array}$ & & & & \\
\hline 23 & $\begin{array}{l}\text { Continuous quality } \\
\text { improvement }\end{array}$ & & & & $\begin{array}{l}\text { [Eliminated } \\
\text { (too broad)] }\end{array}$ \\
\hline 24 & $\begin{array}{l}\text { World Health } \\
\text { Organization guidelines } \\
\text { and models }\end{array}$ & & & & $\begin{array}{l}\text { [Eliminated } \\
\text { (too broad)] }\end{array}$ \\
\hline 25 & $\begin{array}{l}\text { Framework for the } \\
\text { assessment of } \\
\text { sustainability }\end{array}$ & & & & $\begin{array}{l}\text { [Eliminated } \\
\text { (too broad)] }\end{array}$ \\
\hline 26 & System dynamics & & & & $\begin{array}{l}\text { [Eliminated } \\
\text { (too broad)] }\end{array}$ \\
\hline 27 & $\begin{array}{l}\text { Child survival } \\
\text { sustainability assessment } \\
\text { framework }\end{array}$ & & & & $\begin{array}{l}\text { [Eliminated } \\
\text { (not a TMF)] }\end{array}$ \\
\hline \multirow[t]{2}{*}{28} & $\begin{array}{l}\text { HIV/AIDS Program } \\
\text { Sustainability Analysis } \\
\text { Tool }\end{array}$ & & & & $\begin{array}{l}\text { [Eliminated } \\
\text { (not a TMF)] }\end{array}$ \\
\hline & Total score across TMFs & 19 & 29 & 13 & \\
\hline
\end{tabular}

TMF theory, model, and/or framework; T-CaST TMF Comparison and Selection Tool

Of the 28 TMFs (Table 2; TMFs 1-28) used more than once across the 648 studies, 11 TMFs received a T-CaST score of 4 or 5 out of 6 possible points, suggesting potential relevance to understanding sustainment. Nonetheless, the information underlying these quantitative scores warrants some qualitative exploration. We found that sustainment was seldom the outcome of interest in the TMFs used in sustainment studies. This finding may reflect a shortage of TMFs that specifically target sustainment, lack of researcher's familiarity with sustainment-focused TMFs, doubts about their utility, or a preference among researchers for broader TMFs. Whatever the cause, the lack of attention to sustainment as the outcome of interest limits the TMFs' ability to advance our understanding of sustainment. Our understanding of sustainment may be enhanced by converging upon TMFs that include sustainment as the outcome of interest or explicitly acknowledging the limitations for sustainment research of TMFs that include a different outcome. Few of the TMFs explained the mechanisms through which included constructs influence sustainment. Without a strong explanation of the causal pathways that lead to sustainment, the TMFs make limited contributions to identifying and developing potential sustainment strategies. Identifying causal pathways that lead to sustainment implies conceptually sound sustainment strategies. For example, a TMF that suggests that organizations are subject to pressure from norm-setting institutions to sustain a particular practice implies influencing institutional policy as a potentially highleverage strategy. Further, despite evidence suggesting that some conditions are unique in influencing sustainment, few TMFs distinguished determinants of sustainment from determinants of other, related outcomes (e.g., adoption, implementation) [41].

Although 11 TMFs scored fairly well based on our criteria, each had significant limitations. For instance, normalization process theory (NPT), which describes the social processes leading the routinization of EBPs, explains the relationships among included constructs; however, raters had difficulty disentangling NPT's concepts of "integration" and "embeddedness" from its core constructs (e.g., coherence, cognitive participation, collective action, reflexive monitoring). Although normalization in NPT is related to (or perhaps even synonymous with) sustainment, articles that presented NPT did not offer a clear conceptual distinction between "integration" "embeddedness" (i.e., sustainment) and implementation. Another class of TMFs, open systems theories, which broadly propose that organizations are strongly influenced by their environments, offered a 
meaningful, face-valid explanation of sustainment. However, open systems theories did not include discrete constructs, thereby limiting our ability to operationalize or falsify the theory [14]. Further, open systems theories are an umbrella that encompasses several theories, not a singular TMF.

Institutional theory [42-44], which had the highest $\mathrm{T}$-CaST score (5/6), proposes that organizations sustain practices in response to three key pressures related to maintaining legitimacy: mimetic (e.g., mimic other organizations' behavior), coercive (i.e., meet expectations from organizations providing critical resources, including funds and legal permission to operate), and normative (e.g., act in accordance with professional norms). In other words, the institutional theory suggests that organizations may be more likely to sustain practices if they are under mimetic, coercive, or normative pressure to do so. Further, the institutional theory suggests several moderators of the influence of mimetic, coercive, and normative pressure on organizations' sustainment of practices. For example, the institutional theory suggests that organizations may be more inclined to mimic other organizations (i.e., sustaining or failing to sustain a practice) in the face of uncertainty and that organizations may be more inclined to cede to coercive pressure from organizations on which they are more dependent.

Understanding of sustainment may be enhanced by understanding the role of mimetic, coercive, and normative pressures and potential moderators that institutional theory proposes. It may also be enhanced through testing strategies for sustainment that the institutional theory suggests: Sustainment may be promoted by assessing the pressures to which an organization may be subject with respect to sustaining a given EBP and then leveraging pressures for sustainment and deflecting those for discontinuation of the EBP.

Despite its potential contribution to understanding sustainment, institutional theory offers limited insight into potentially influential factors at levels other than the outer setting, including the inner setting and individual levels. To some extent, neo-institutional theory [45] may address this limitation. For example, neoinstitutional theory suggests that individuals make choices because they see no alternative. Psychological theories, such as theories concerning habits [46], may also offer insight into individual-level determinants of sustainment. Another important critique of the institutional theory is that the institutional pressures that it conceptualizes may be sufficient for superficial organizational change, but sustaining practice may require more intrinsic motivations [47, 48]. The limitations of the institutional theory-or any given TMFsuggests that combining multiple relevant TMFs may be an optimal approach to conceptualizing a construct as complex as sustainment.

Notably, the TMFs that appear to be most relevant to sustainment focus on social dynamics among individuals and organizations. Although sustainment is often inextricably linked with economic resources for delivering EBPs, economic theories for explaining sustainment did not emerge in this review [8]. Indeed, stable financial resources are necessary for sustainment, but our findings highlighting the importance of social processes and relationships suggest that economic and rational choice theories are likely insufficient for explaining whether and how EBPs are sustained in such complex care settings.

A limitation of our study is that there may be other TMFs that are relevant for understanding sustainment but have not yet been cited in healthcare sustainment research. For example, structuration theory [49] explains how social systems create and reproduce structures that uphold and discontinue EBPs. The structuration theory has the benefit of a multilevel orientation to understanding EBP sustainment. Similarly, the contingency theory suggests that EBP sustainment depends on conditions that incentivize sustainment in the face of competing courses of action. Future efforts should assess the relevance of other potentially relevant TMFs for conceptualizing sustainment. And, as the evidence base around sustainment grows, and TMFs are more widely used to support it, the field may benefit from identifying examples of sustainment studies that have effectively applied TMFs.

In this study, we treated TMFs as distinct although we recognize that there are areas of overlap of constructs across TMFs. Identifying overlap of constructs across TMFs may be aided by ongoing efforts to assess the validity and reliability of measures of sustainment-related constructs [50]. Further, as a review of reviews, our study relied upon the information that included the review provided by the authors regarding how TMFs were used in included studies. The degree to which TMFs were used can vary from mere citation to rigorous testing and linkage to specific constructs. Although this level of detail was beyond the scope of our study, we acknowledge the significance of this area for future research. Relatedly, despite the potential for reviews of reviews to leverage existing reviews to develop new knowledge, it is possible that our review of reviews [51, 52] was not entirely comprehensive, and we did not independently review methodological quality.

Another limitation of our study is that, with the exception of the studies cited by Shigayeva and Coker (2015) [17], we did not independently evaluate studies included in the remaining eight reviews. Thus, our estimate of the proportion of studies citing TMFs relies on these reviews' findings, and the number of studies that we report may include duplicates. Consequently, for the proportion 
of studies citing TMFs, both the denominator and the numerator may be overestimates; however, the proportion that we report is likely valid. Although we documented assessments of quality conducted by authors of included reviews in Table 1, we did not independently evaluate the quality of published reviews. To the extent that extant reviews' quality is limited, our findings may not accurately reflect the use of TMFs or their relevance for sustainment research. Nevertheless, our work represents an effort to consolidate existing knowledge to answer novel questions as implementation scientists increasingly appreciate the importance of sustainment.

We used T-CaST to rate the performance of TMFs identified in the review from our own perspectives. Future work should evaluate the relevance of sustainment TMFs from the perspectives of users; users' perspectives of TMFs' relevance for their work (e.g., whether they use TMFs for data collection and/or analysis) may enhance our understanding of TMFs' contributions to conceptualizing sustainment.

\section{Conclusion}

Leveraging published reviews of sustainment studies, we identified institutional theory as a promising TMF for advancing our understanding of sustainment. Incorporating theories that meet the criteria that we advanced above has the potential to promote shared understanding of EBP sustainment. Shared understanding of EBP sustainment will be enhanced by repeatedly applying a few sustainment theories. To limit the synonymy and polysemy that has fractured our understanding to date, we must also agree upon operational definitions of included constructs. Then, we may be able to compare the performance of selected theories and understand the implications of sustainment research for identifying promising sustainment strategies.

\section{Abbreviations \\ EBP: Evidence-based practice; T-CaST: Theory, Model, and Framework Comparison and Selection Tool; TMF: Theory, model, and/or framework}

\section{Acknowledgements}

The authors would like to thank Lauren Richardson for her assistance in abstracting information regarding theories, models, and frameworks from empirical articles included in Shigayeva and Corker [31] and Michael I. Harrison for his contributions to the conceptualization, analysis, and interpretation of study results.

\section{Authors' contributions}

All authors made significant contributions to the manuscript. SB, EH, and $\mathrm{SH}$ collected the data. SB, EH, SH, and $\mathrm{MH}$ analyzed the data. SB, EH, SH, DC, AB, $\mathrm{MH}$, and PN drafted and critically revised the manuscript for important intellectual content. All authors have read and given final approval of the version of the manuscript submitted for publication.

\section{Funding}

Dr. Birken's effort was supported by the National Center for Advancing Translational Sciences, National Institutes of Health, through Grant KL2TR002490. The content is solely the responsibility of the authors and does not necessarily represent the official views of the $\mathrm{NIH}$.
Availability of data and materials

Data abstracted for this review as a supporting file.

\section{Ethics approval and consent to participate}

Human subjects were not included in this study.

\section{Consent for publication}

Individual data were not included in this study.

\section{Competing interests}

The authors declare that they have no competing interests. Dr. Chambers authored one of the reviews included in this study: The dynamic sustainability framework: addressing the paradox of sustainment amid ongoing change (https://implementationscience.biomedcentral.com/ articles/10.1186/1748-5908-8-117).

\section{Author details}

${ }^{1}$ Department of Health Policy and Management, Gillings School of Global Public Health, The University of North Carolina at Chapel Hill, 1103E McGavran-Greenberg, 135 Dauer Drive, Campus Box 7411, Chapel Hill, NC 27599-7411, USA. ${ }^{2}$ Department of Health Policy and Management, The University of North Carolina at Chapel Hill, 1101B McGavran - Greenberg Hall, CB\# 7411, Chapel Hill, NC 27599-7411, USA. ${ }^{3}$ Division of Cancer Control and Population Sciences, National Cancer Institute, 9609 Medical Center Drive, Room 3E414, Rockville, MD 20850, USA. ${ }^{4}$ College of Social Work, The Ohio State University, 1947 College Road, Columbus, OH 43210, USA. ${ }^{5}$ Department of Medical and Health Sciences, Division of Community Medicine, Linköping University, SE-581 83 Linköping, Sweden.

Received: 17 January 2020 Accepted: 31 August 2020

Published online: 09 October 2020

\section{References}

1. Group E-BMW. Evidence-based medicine. A new approach to teaching the practice of medicine. JAMA. 1992;268(17):2420

2. Aarons GA, Hurlburt M, Horwitz SM. Advancing a conceptual model of evidence-based practice implementation in public service sectors. Adm Policy Ment Health Ment Health Serv Res. 2011;38(1):4-23.

3. Chambers DA, Glasgow RE, Stange KC. The dynamic sustainability framework: addressing the paradox of sustainment amid ongoing change. Implement Sci. 2013;8(1):117.

4. Proctor $\mathrm{E}$, Silmere $\mathrm{H}$, Raghavan $\mathrm{R}$, et al. Outcomes for implementation research: conceptual distinctions, measurement challenges, and research agenda. Admin Pol Ment Health. 2011;38(2):65-76

5. Buchanan D, Fitzgerald L, Ketley D, et al. No going back: a review of the literature on sustaining organizational change. Int J Manag Rev. 2005;7(3): 189-205.

6. Goodman RM, Steckler A. A framework for assessing program institutionalization. Knowledge Soc. 1989:2(1):57-71.

7. LaPelle NR, Zapka J, Ockene JK. Sustainability of public health programs: the example of tobacco treatment services in Massachusetts. Am J Public Health. 2006;96(8):1363-9.

8. Wiltsey Stirman S, Kimberly J, Cook N, Calloway A, Castro F, Charns M. The sustainability of new programs and innovations: a review of the empirical literature and recommendations for future research. Implement Sci. 2012;7: 17.

9. Massatti RR, Sweeney HA, Panzano PC, Roth D. The de-adoption of innovative mental health practices (IMHP): why organizations choose not to sustain an IMHP. Adm Policy Ment Health Ment Health Serv Res. 2008;35(12):50-65.

10. Scheirer MA. Linking sustainability research to intervention types. Am J Public Health. 2013;103(4):e73-80.

11. Hearld $L R$, Bleser $W K$, Alexander $J A$, Wolf $L$. A systematic review of the literature on the sustainability of community health collaboratives. Med Care Res Rev. 2015;73(2):127-81.

12. Greenhalgh T, Robert G, Macfarlane F, Bate P, Kyriakidou O. Diffusion of innovations in service organizations: systematic review and recommendations. Milbank Q. 2004;82(4):581-629.

13. May C. Towards a general theory of implementation. Implement Sci. 2013; $8(1): 18$ 
14. Birken SA, Powell BJ, Shea CM, et al. Criteria for selecting implementation science theories and frameworks: results from an international survey. Implement Sci. 2017;12(1):124.

15. Nadalin Penno L, Davies B, Graham ID, et al. Identifying relevant concepts and factors for the sustainability of evidence-based practices within acute care contexts: a systematic review and theory analysis of selected sustainability frameworks. Implement Sci. 2019;14(1):108.

16. Moore JE, Mascarenhas A, Bain J, Straus SE. Developing a comprehensive definition of sustainability. Implement Sci. 2017;12(1):110.

17. Shigayeva A, Coker RJ. Communicable disease control programmes and health systems: an analytical approach to sustainability. Health Policy Plan. 2015;30(3):368-85.

18. Birken SA, Rohweder CL, Powell BJ, et al. T-CaST: an implementation theory comparison and selection tool. Implement Sci. 2018;13(1):143.

19. Tricco AC, Ashoor HM, Cardoso R, et al. Sustainability of knowledge translation interventions in healthcare decision-making: a scoping review. Implement Sci. 2016;11(1):55.

20. Hulland K. What factors affect sustained adoption of safe water, hygiene and sanitation technologies? A systematic review of literature; 2015.

21. Lovarini M, Clemson L, Dean C. Sustainability of community-based fall prevention programs: a systematic review. J Saf Res. 2013;47:9-17.

22. Iwelunmor J, Blackstone S, Veira D, et al. Toward the sustainability of health interventions implemented in sub-Saharan Africa: a systematic review and conceptual framework. Implement Sci. 2016;11(1):43.

23. Schell SF, Luke DA, Schooley MW, et al. Public health program capacity for sustainability: a new framework. Implement Sci. 2013;8(1):15.

24. Hodge Lauren M, Turner Karen MT. Sustained implementation of evidencebased programs in disadvantaged communities: a conceptual framework of supporting factors. Am J Community Psychol. 2016;58(1-2):192-210.

25. Moher D, Liberati A, Tetzlaff J, Altman DG, Group P. Preferred Reporting Items for Systematic Reviews and Meta-Analyses: the PRISMA statement PLoS Med. 2009;6(7):e1000097.

26. Lennox L, Maher L, Reed J. Navigating the sustainability landscape: a systematic review of sustainability approaches in healthcare. Implement Sci. 2018;13:27.

27. Rosenstock IM. Historical origins of the health belief model. Health Educ Monogr. 1974;2(4):328-35.

28. Ajzen I. From intentions to actions: a theory of planned behavior. In: Kuhl J, Beckmann J, editors. Action control: from cognition to behavior. Berlin: Springer Berlin Heidelberg; 1985. p. 11-39.

29. May CR, Mair F, Finch T, et al. Development of a theory of implementation and integration: normalization process theory. Implement Sci. 2009;4(1):29.

30. Martin NA, Hulland KR, Dreibelbis R, Sultana F, Winch PJ. Sustained adoption of water, sanitation and hygiene interventions: systematic review. Tropical Med Int Health. 2018;23(2):122-35.

31. Goodman RM, Steckler A. A model for the institutionalization of health promotion programs. Fam Commun Health. 1989;11(4):63-78.

32. Rogers EM. Diffusion of innovations, vol. 2003. New York: Free Press; 2003.

33. Scott WR, Davis GF. Organizations and organizing: rational, natural, and open system perspectives. Upper Saddle River: Pearson Prentice Hall, c2007; 2007.

34. Argyris C, Schön DA. Organizational learning: a theory of action perspective. Boston: Addison-Wesley Publishing Company; 1978.

35. Salancik GR. WANTED: a good network theory of organization. Adm Sci Q. 1995;40(2):345-58

36. Cella-De-Oliveira FA. Indicators of organizational sustainability: a proposition from organizational competences. Int Rev Manag Business Res. 2013;2:18.

37. Feldman MS, Pentland BT. Reconceptualizing organizational routines as a source of flexibility and change. Adm Sci Q. 2003;48(1):94-118.

38. Davies P, Walker AE, Grimshaw JM. A systematic review of the use of theory in the design of guideline dissemination and implementation strategies and interpretation of the results of rigorous evaluations. Implement Sci. 2010; 5(1):14.

39. Colquhoun HL, Letts LJ, Law MC, MacDermid JC, Missiuna CA. A scoping review of the use of theory in studies of knowledge translation. Can J Occupational Ther. 2010;77(5):270-9.

40. Tinkle M, Kimball R, Haozous EA, Shuster G, Meize-Grochowski R. Dissemination and Implementation Research Funded by the US National Institutes of Health, 2005-2012. Nurs Res Pract. 2013;2013:909606. https://doi.org/10.1155/2013/909606.
41. Shediac-Rizkallah MC, Bone LR. Planning for the sustainability of community-based health programs: conceptual frameworks and future directions for research, practice and policy. Health Educ Res. 1998;13(1):87108.

42. Powell WW, Di Maggio PJ. The new institutionalism in organizational analysis. Chicago: University of Chicago Press; 1991.

43. DiMaggio PJ, Powell WW. The iron cage revisited: institutional isomorphism and collective rationality in organizational fields. Am Sociol Rev. 1983;48(2): 147-60.

44. Meyer JW, Rowan B. Institutionalized organizations: formal structure as myth and ceremony. Am J Sociol. 1977:83(2):340-63.

45. Greenwood R, Hinings CR. Understanding radical organizational change: bringing together the old and the new institutionalism. Acad Manag Rev. 1996;21(4):1022-54.

46. Nilsen P, Roback K, Broström A, Ellström P-E. Creatures of habit: accounting for the role of habit in implementation research on clinical behaviour change. Implement Sci. 2012;7(1):53.

47. Keast R, Mandell MP, Brown K, Woolcock G. Network structures: working differently and changing expectations. Public Adm Rev. 2004;64(3):363-71.

48. Provan KG, Isett KR, Milward HB. Cooperation and compromise: a network response to conflicting institutional pressures in community mental health. Nonprofit Volunt Sect Q. 2004:33(3):489-514.

49. Giddens A. The constitution of society: outline of the theory of structuration. Berkeley: University of California Press; 1984.

50. Lewis CC, Stanick CF, Martinez RG, et al. The Society for Implementation Research Collaboration Instrument Review Project: a methodology to promote rigorous evaluation. Implement Sci. 2015;10:2.

51. Smith V, Devane D, Begley CM, Clarke M. Methodology in conducting a systematic review of systematic reviews of healthcare interventions. BMC Med Res Methodol. 2011;11(1):15.

52. Aromataris E, Fernandez R, Godfrey CM, Holly C, Khalil H, Tungpunkom P. Summarizing systematic reviews: methodological development, conduct and reporting of an umbrella review approach. Int J Evid Based Healthc. 2015;13(3):132-40

\section{Publisher's Note}

Springer Nature remains neutral with regard to jurisdictional claims in published maps and institutional affiliations.
Ready to submit your research? Choose BMC and benefit from:

- fast, convenient online submission

- thorough peer review by experienced researchers in your field

- rapid publication on acceptance

- support for research data, including large and complex data types

- gold Open Access which fosters wider collaboration and increased citations

- maximum visibility for your research: over $100 \mathrm{M}$ website views per year

At $\mathrm{BMC}$, research is always in progress.

Learn more biomedcentral.com/submissions 